\title{
Palladium nano-clusters grown on prestructured HOPG substrates
}

\author{
Z. Yuan ${ }^{1}$, R. Stephan ${ }^{1, a}$, M.C. Hanf ${ }^{1}$, J.M. Becht ${ }^{1}$, C. Le Drian ${ }^{1}$, M. Hugentobler ${ }^{2}$, W. Harbich ${ }^{2}$, and P. Wetzel ${ }^{1}$ \\ 1 IS2M LRC CNRS 7228 - UHA, 15 rue Jean Starcky, 68057 Mulhouse, France \\ 2 ICMP, École Polytechnique Fédérale de Lausanne, 1015 Lausanne, Switzerland
}

Received 24 February 2011 / Received in final form 4 May 2011

Published online 28 June 2011 - (C) EDP Sciences, Società Italiana di Fisica, Springer-Verlag 2011

\begin{abstract}
The growth of Palladium nano-clusters prepared by atomic beam deposition on prestructured highly oriented pyrolytic graphite (HOPG) surfaces has been investigated by means of scanning tunnelling microscopy (STM). Preformed nanosized pits created on the HOPG surfaces are used as localized pinning sites for Pd cluster nucleation and growth at room temperature. We succeeded in obtaining Pd clusters of nanometric size and with rather sharp size distributions. A systematic morphological study conducted by STM reveals a linear dependence between the height and the diameter of the Pd nanostructures. Finally, $\mathrm{Pd}$ nano-clusters stabilized on prestructured HOPG surfaces were found to be active catalysts in the Heck cross-coupling reaction.
\end{abstract}

\section{Introduction}

The improvement of the catalytic properties of noble metals is a major topic in a context of sustainable development and rarity of noble metals. Recent modelling and experimental studies suggest that noble metal effectiveness factor may be significantly improved by an optimization of the architecture of the catalytic layer and of the noble metal distribution within the catalytic layer $[1,2]$. Indeed, the latter has a strong impact on the mass transport of the reactant molecules and products and on the coupling between the catalytically active sites. One of the promising ideas is to obtain a regular spatial distribution of Pd nanoparticles on HOPG substrate, whereby Pd interparticle coupling mechanisms and their influence on the $\mathrm{Pd}$ catalysis reaction rate could be quantitatively studied. These results will be of key importance for the understanding of the relations between the intrinsic catalytic activity of an isolated particle and the properties of more complex architectures.

Moreover, the catalytic properties of metallic particles are known, in certain circumstances, to be enhanced when the cluster size is reduced [3-8]. The most famous case is gold whose bulk form is inert whereas small particles can be chemically active [9-15]. In the case of $\mathrm{Pd}$, it has been reported that Pd nanoparticles supported by different substrates exhibit high catalytic activities for many chemical reactions [16-20]. Size effect is observed for both supported [21] and unsupported Pd particles [22], which has been attributed to various phenomena such as specific electronic structure of the nanoparticles as well as particles surface structure modifications. From those results, it is clear that the support on which the particles are deposited may also play a major role in the catalytic activity. Thus it is a major issue to be able to control the size of the clusters. Now the basal plane of HOPG, which has all carbon bonds saturated, is extremely inert and allows adatom diffusion because of a small corrugation. This is a very appreciable property for a catalyst support but, consequently, it is difficult to stabilize nanoparticles on the surface terraces of HOPG [23], and aggregation under high vacuum conditions takes place at monoatomic step edges $[24,25]$. This results in the formation of nanoparticles with a low density. Moreover, their size will be difficult to control and they will be anisotropically distributed like metallic chains [26]. A possible solution is to stabilize these very small particles via defects on the surface [27-31]. If partial implantation of the cluster atoms allows a relative stability under vacuum conditions at room temperature, structures created by this mean alter upon exposure to atmospheric conditions or when immersed in solutions. Instead, strongly nanostructured surfaces of HOPG, generally considered as a model, can be used as substrates. Kappes and coworkers [32,33] were the first to produce controlled nanosized pits obtained by selective etching of defects created in HOPG by ion bombardment. Hövel's group has used etched pits as high-density anchoring sites in order to study the morphology and electronic structure of gold clusters in great details [34,35]. More recently Harbich et al. used this prestructured template to study the morphology and the stability of Au clusters grown in multilayer deep HOPG nanopits, and the etching of

\footnotetext{
a e-mail: regis.stephan@uha.fr
} 
graphene layers by the Au particles upon annealing at high temperatures under ambient conditions [36,37].

In this paper, we report on the preparation of nanosized Pd particles grown on a prestructured HOPG substrate by atomic beam deposition in soft landing conditions. Using STM, we investigated the influence of various parameters such as $\mathrm{Pd}$ quantity or pits size on the morphology and size of the Pd nano-clusters. We demonstrate that the pit rims are preferential nucleation sites for $\mathrm{Pd}$ particles growth. We also observed that the increase of the Pd deposited quantity leads to an increase of the number of particles until saturation of the pits. Moreover, the diameter distribution remains relatively small (about $2.5 \mathrm{~nm}$ ) even after annealing to $500 \mathrm{~K}$. Finally, preliminary results indicate that $\mathrm{Pd}$ clusters grown on $\mathrm{HOPG}$ present a catalytic activity in the Heck cross-coupling reaction.

\section{Experiment}

HOPG samples used as substrates are provided by Goodfellow. The samples are prepared by a two steps process. During the first step, the samples are cleaved with adhesive tape shortly before introduction in vacuum. Then, the clean HOPG surfaces are exposed to $\mathrm{Au}_{5}$ clusters with an appropriate kinetic energy $(\sim 3 \mathrm{keV})$. The cluster source is described elsewhere [38]. The bombardment involves the creation of dangling bonds induced by the damaged graphite areas which serve as starting sites for $\mathrm{O}_{2}$ oxidation for the following etching step. The defects are then opened into nanosized pits by oxidative etching carried out at around $900 \mathrm{~K}$ [39]. The appealing advantage of that method is that the depth, and so the number of dangling bonds, can be selected with a very good precision. The lateral size of the pits is controlled via the exposure time while the pit density can be controlled via the bombarding time. A detailed description of the preformed HOPG surface preparation has been reported previously [39]. In the second step, Pd nanoclusters are grown on the prestructured HOPG substrates. The samples are put in a two-chamber ultrahigh vacuum system consisting of an evaporation chamber connected with a scanning tunnelling microscope. Pd is deposited at room temperature (RT) on the HOPG surface from a Knudsen effusion cell where an $\mathrm{Al}_{2} \mathrm{O}_{3}$ crucible was heated by electron-beam. A slow deposition rate of $\sim 0.02 \mathrm{ML} \mathrm{min}^{-1}$ recorded with a crystal thickness monitor was used for all experiments. One monolayer (ML) coverage corresponds to $3.8 \times 10^{15}$ atoms $\mathrm{cm}^{-2}$, i.e., the atomic density of the HOPG(0001) surface. STM imaging of the samples was performed using an Omicron microscope operated at room temperature in UHV with a base pressure in the $10^{-10}$ mbar range. STM images were acquired in constant-current mode using tunnelling tungsten tips prepared by chemical etching and annealing in UHV. The images were analyzed using the WSxM [40] software package. Due to inevitable tip convolution, the real particle size and shape are difficult to measure and therefore it should be kept in mind that the values obtained in the present work are overestimated. Cluster height is defined

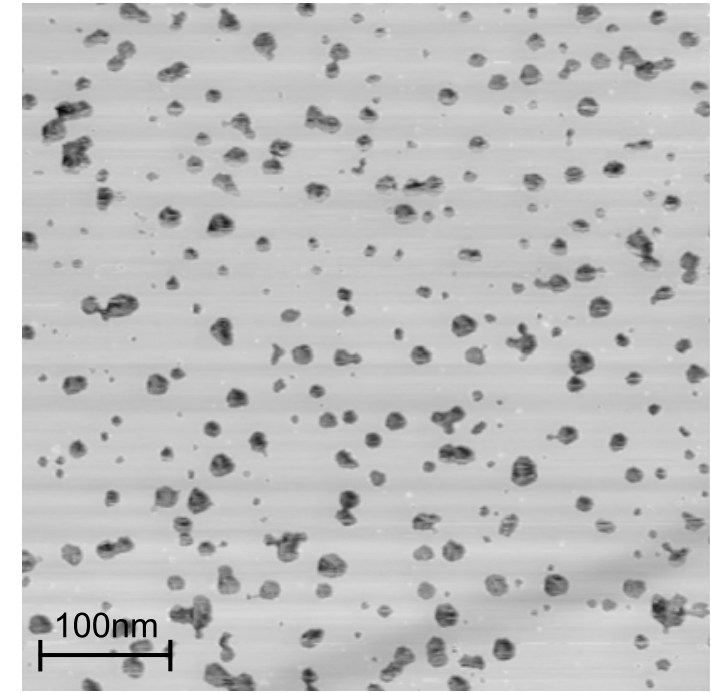

Fig. 1. STM image of a HOPG surface with artificially generated pits $U_{\text {gap }}=0.51 \mathrm{~V}, I_{T}=0.38 \mathrm{nA}(500 \mathrm{~nm} \times 500 \mathrm{~nm})$.

as the distance between the top of the cluster and the rim of the pit. It should be noted that all those quantities were measured from STM images by taking line profiles across each of the clusters.

\section{Results and discussion}

A first experiment consists in Pd deposition at RT on a ascleaved HOPG sample. A clear step and terrace morphology is observed with well defined steps and atomically flat terraces running over more than $500 \mathrm{~nm}$. After Pd condensation, aligned protrusions are observed, which evidences that Pd clusters nucleate exclusively at the step edge sites with no apparent clusters at terraces. This result indicates that Pd deposited at RT diffuses freely on the HOPG surface and reaches the step edges where nucleation and growth of $\mathrm{Pd}$ nano-clusters take place. The decoration of step edges with $\mathrm{Pd}$ nano-clusters grown on HOPG has been previously observed by Whelan and Barnes [41]. In other words, Pd clusters tend to grow on HOPG defects, here step edges, which are strong nucleation sites because they exhibit dangling bonds.

As mentioned previously, in order to study the physical or chemical properties of nano-objects, it is necessary to be able to grow a large number of $\mathrm{Pd}$ nanostructures with well defined size. This requires to limit diffusion of the deposited $\mathrm{Pd}$ on the surface. One possible approach is to increase the density of defects in the surface layer which might serve as efficient anchoring sites for nucleation and growth of the clusters. In the present work we have used HOPG prestructured templates exhibiting pit defects generated by implantation of size-selected Au clusters in HOPG [39].

Figure 1 shows a typical STM image of a HOPG template obtained by bombardment with $\mathrm{Au}_{5}$ clusters followed by oxidation at $950 \mathrm{~K}$ for $5 \mathrm{~min}$. We can clearly observe pits created on the terrace by lateral etching. The pits appear circular in shape, with diameters from 5 

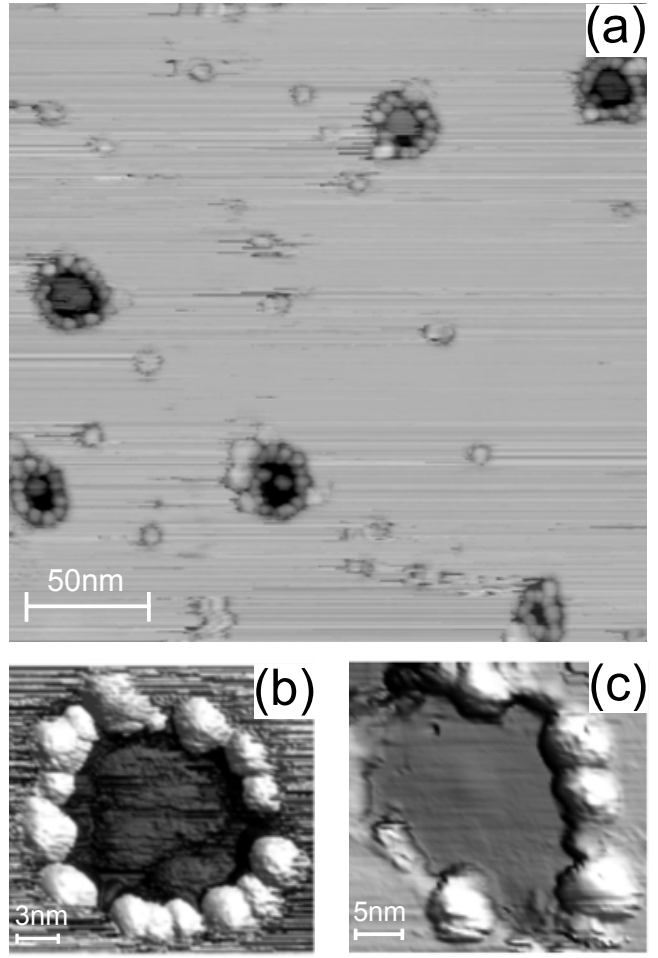

Fig. 2. STM image of prestructured HOPG surfaces after deposition at RT of (a) $0.75 \mathrm{ML}$, (b) $0.75 \mathrm{ML}$, (c) $0.5 \mathrm{ML}$ of $\mathrm{Pd}\left((\mathrm{a}): U_{\text {gap }}=-0.7 \mathrm{~V}, I_{T}=0.14 \mathrm{nA}, 250 \mathrm{~nm} \times 250 \mathrm{~nm}\right.$; (b): $U_{\text {gap }}=-1.6 \mathrm{~V}, I_{T}=0.43 \mathrm{nA}, 20 \mathrm{~nm} \times 20 \mathrm{~nm}$; (c): $\left.U_{\text {gap }}=-0.51 \mathrm{~V}, I_{T}=0.14 \mathrm{nA}, 30 \mathrm{~nm} \times 30 \mathrm{~nm}\right)$.

to $17 \mathrm{~nm}$ and with depths from 2 to 4 monolayers. The mean total defects length is found to be about $40 \mu \mathrm{m}$ per $\mu \mathrm{m}^{2}$, whereas it is only 2 to $4 \mu \mathrm{m}$ per $\mu \mathrm{m}^{2}$ for HOPG surfaces presenting natural steps. Thus the metal clusters density obtained after $\mathrm{Pd}$ deposition will be higher on prestructured surfaces than on as-cleaved ones. Moreover, the Pd structures which are grown on prestructured HOPG are expected to be pinned more strongly than on monoatomic steps, as the latter present less anchoring sites than the several monolayers deep pits.

The STM image in Figure 2a shows the prestructured HOPG surface after deposition at room temperature of $0.75 \mathrm{ML} \mathrm{Pd}$. We observe the formation of $\mathrm{Pd}$ clusters which appear in the shape of small spherical protrusions. Majority of the clusters are located near the edge of the pits with a few on the flat terrace. The horizontal bright streaks, also observed on Figure 3a, can be attributed to an artifact. Nevertheless, this has been taken into account for height and diameter measurements by using reference objects like for example monoatomic steps.

Figure 3a shows another part of the surface of the sample. This image exhibits clusters decorating the edge of the pits along with the edge of a step. Figure $3 \mathrm{~b}$ shows the line profile for a typical decorated pit. Note that for this coverage the total amount of pit and step edge defect sites is saturated. In addition, besides the strong decoration of steps, many separate clusters of comparable size are visible on the terraces. Figure $2 \mathrm{~b}$ shows a typical STM image
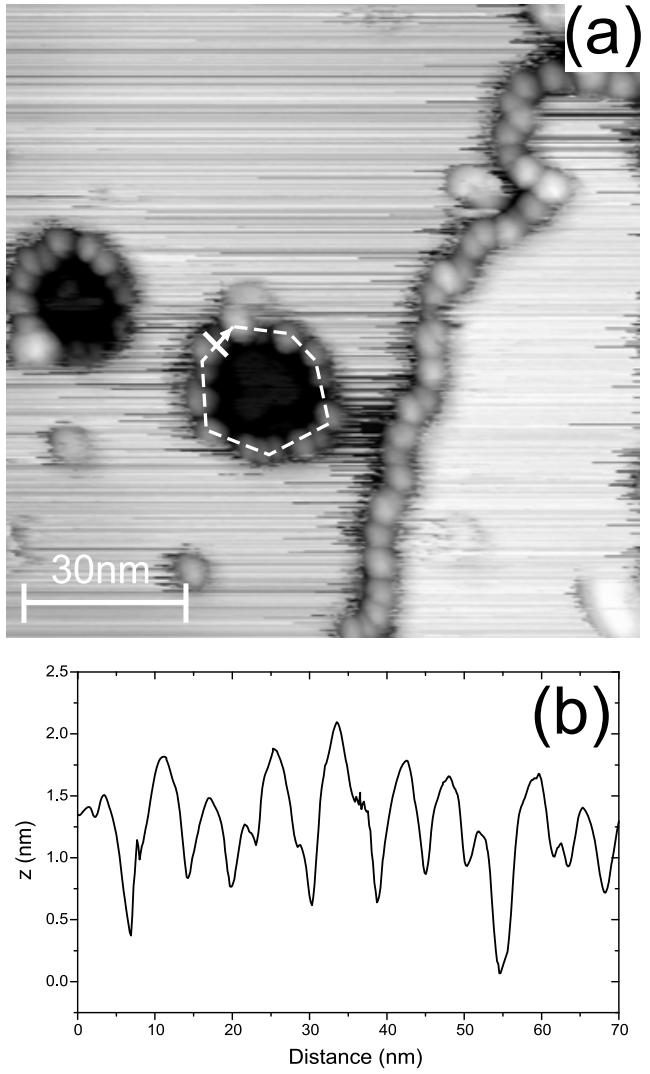

Fig. 3. (a) STM image of a prestructured HOPG surface after deposition at RT of $0.75 \mathrm{ML} \mathrm{Pd}\left(U_{\text {gap }}=-0.52 \mathrm{~V}, I_{T}=0.14 \mathrm{nA}\right.$ $(110 \mathrm{~nm} \times 110 \mathrm{~nm}))(\mathrm{b})$ line profile of the decorated pit indicated by the white dashed line in (a). Start point and profile line direction are given by the white bar and arrow respectively.

of a pit decorated with $\mathrm{Pd}$ clusters which are arranged like beads in a collar. As a result of the Pd deposition at RT the $\mathrm{Pd}$ clusters aggregate into ordered one dimensional chain along the rim edge of the pits as well as along the step edges.

Figure 2c shows a STM image of 0.5 ML Pd deposited at room temperature on a prestructured HOPG surface. As can be seen the $\mathrm{Pd}$ clusters are located at the pit edge as well. However, for this coverage the periphery of the pit is not totally saturated with $\mathrm{Pd}$ clusters as for $0.75 \mathrm{ML}$ of Pd. In other words, the number of clusters per pit (for a given pit diameter), or cluster number per perimeter unit, increases with $\mathrm{Pd}$ coverage until pit saturation. Figure $4 \mathrm{a}$ and $4 \mathrm{~b}$ show the diameter distribution histograms of $\mathrm{Pd}$ nano-clusters anchored around pit rim edges for Pd deposits at RT of 0.75 and $0.5 \mathrm{ML}$, respectively. The histogram obtained after annealing the sample corresponding to $0.5 \mathrm{ML}$ at $500 \mathrm{~K}$ is also presented in Figure $4 \mathrm{~b}$. The data have been taken on several scanned areas, and several hundred clusters have been analyzed for each histogram to obtain significant statistics. The mean diameters obtained after fitting the histograms with Gaussian distributions are found rather close for both $\mathrm{Pd}$ coverages, i.e. 4.7 and $4.1 \mathrm{~nm}$ for $0.75 \mathrm{ML}$ and $0.5 \mathrm{ML}$, respectively. The distribution widths are very similar as 

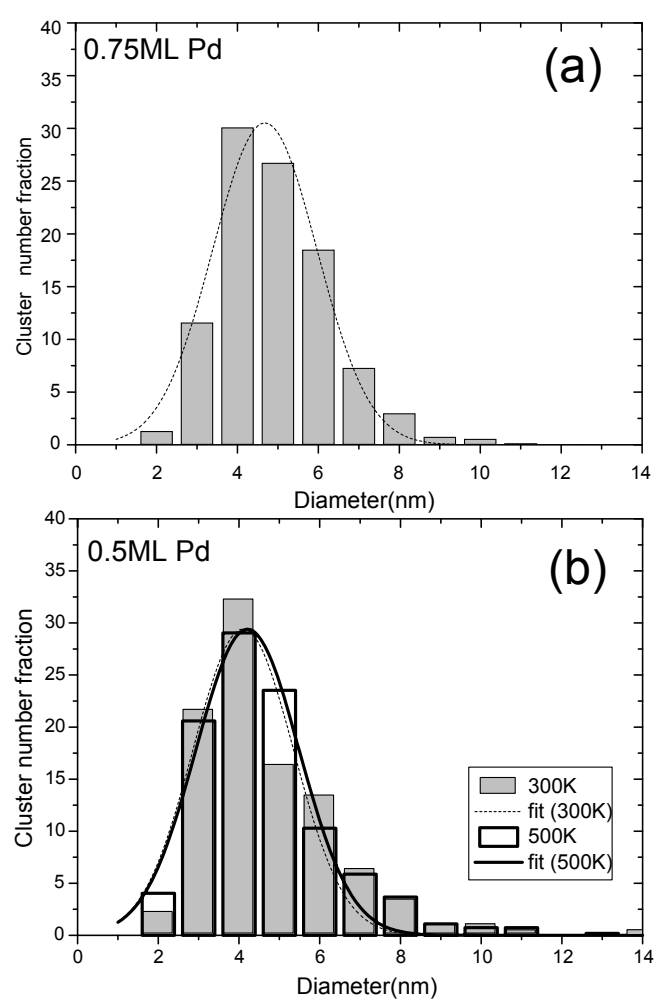

Fig. 4. Histograms of the cluster diameter distribution for clusters found around pits and for a deposit of (a) 0.75 ML Pd at $300 \mathrm{~K}$ (b) $0.5 \mathrm{ML} \mathrm{Pd}$ at $300 \mathrm{~K}$ and after annealing at $500 \mathrm{~K}$.

well (2.6 and $2.5 \mathrm{~nm}$, respectively). Thus, for increasing $\mathrm{Pd}$ coverage $(<0.75 \mathrm{ML})$, the cluster number per perimeter unit increases rather than the cluster size.

To investigate the influence of temperature on the $\mathrm{Pd}$ nano-clusters grown on the prestructured HOPG surfaces the samples were annealed at $500 \mathrm{~K}$ for $20 \mathrm{~min}$. After this annealing step, the shape and the density of the Pd clusters decorating pits did not change significantly. Moreover, as can be seen in Figure $4 \mathrm{~b}$, the mean diameters are unchanged after annealing, as well as the width of the distribution, indicating that the particles did not coalesce into larger clusters. These results suggest that Pd clusters are firmly anchored at the dangling bonds of the defects and are stable for temperatures up to $500 \mathrm{~K}$.

As already pointed out before, besides the strong pit and edge decorations, very few separate Pd clusters appear on the terraces. These individual clusters are probably located on top of very small pits (with a diameter lower than $5 \mathrm{~nm}$ ) or/and on natural HOPG point defects in the top layers of HOPG. Figure 5 a shows a typical three dimensional STM image of $0.25 \mathrm{ML}$ Pd deposited at room temperature on a HOPG surface prestructured with pits with diameter smaller than $5 \mathrm{~nm}$. It can be seen that the pattern formed by those small pits is very similar to the one formed by the pits before $\mathrm{Pd}$ deposition. Figure $5 \mathrm{~b}$ presents the cluster diameter distribution after $\mathrm{Pd}$ deposit at $300 \mathrm{~K}$, which is centered at $5.3 \mathrm{~nm}$ indicating that the particles growing on top of small pits are slightly larger than those decorating the larger circular defects.

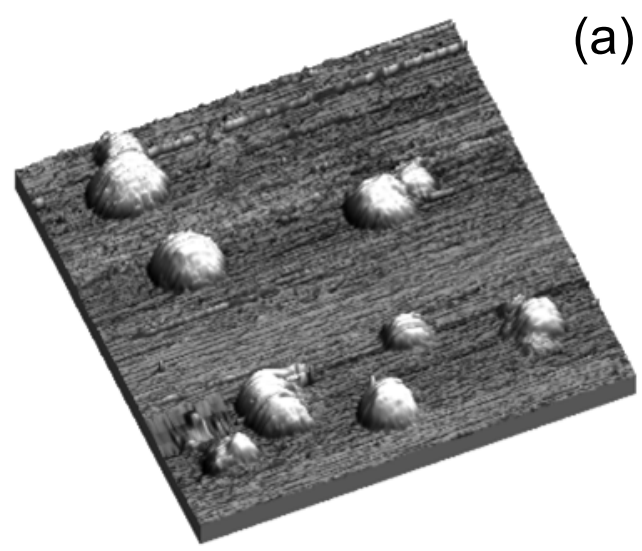

(a)

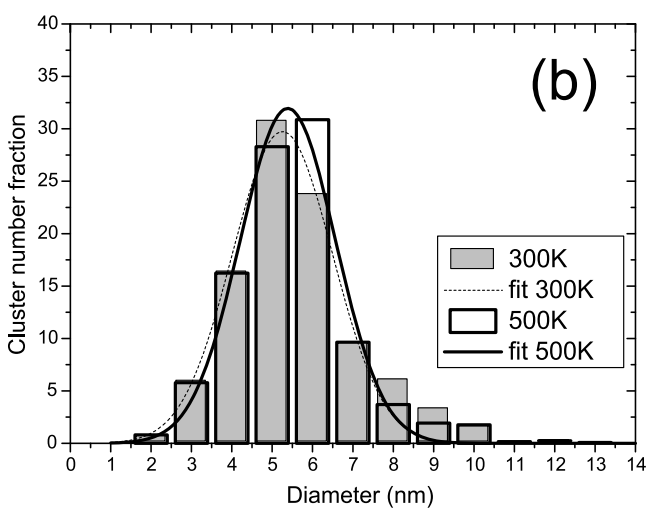

Fig. 5. (a) STM image of a prestructured HOPG surface after deposition at RT of $0.25 \mathrm{ML} \mathrm{Pd}$ on a surface displaying only pits with diameters smaller than $5 \mathrm{~nm}\left(U_{\text {gap }}=-4.0 \mathrm{~V}\right.$, $\left.I_{T}=0.3 \mathrm{nA}(42 \mathrm{~nm} \times 42 \mathrm{~nm})\right)$. (b) Related histograms of the cluster diameter measured after deposition at $300 \mathrm{~K}$ and after annealing at $500 \mathrm{~K}$.

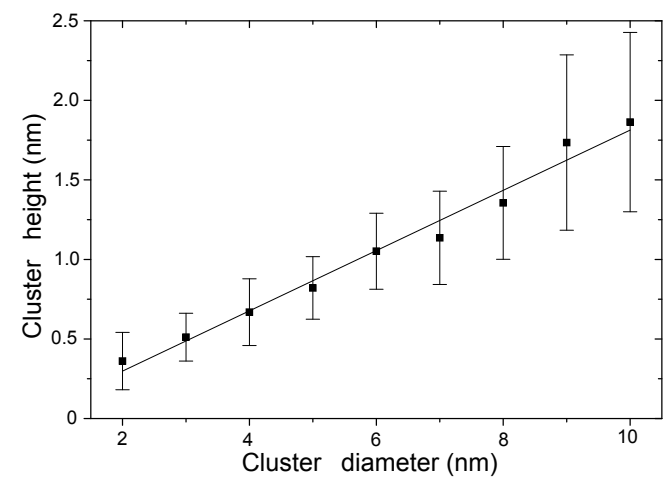

Fig. 6. Mean height of the Pd clusters as a function of diameter. Error bars correspond to standard deviation values.

However, according to Figure 5b, the diameter distribution of these clusters is not modified when the system is annealed at $500 \mathrm{~K}$, as for the particles forming a collar around the large pits.

Finally, interesting results come also from the study of the dependence between the height and the diameter of the Pd nano-clusters. Figure 6 displays mean height of the $\mathrm{Pd}$ clusters as a function of their diameter. It should be noted that the data set was obtained by averaging over a 
<smiles>C=CC(=O)OC</smiles>

HOPG $\overrightarrow{\mathrm{Et}_{3} \mathrm{~N} \text {, Toluene / DMF }(2: 1)}$ $100^{\circ} \mathrm{C}, 12 \mathrm{~h}$

large sample of clusters measured on multiple STM images taken for different experimental preparations (different $\mathrm{Pd}$ coverages and different pit diameters), each carried out on a freshly prepared prestructured HOPG surface. The error bars correspond to standard deviation values. The results clearly indicate that independently of the considered $\mathrm{Pd}$ coverage and of the pit diameters, the mean height $\mathrm{h}$ is a linear function of the cluster diameter $d$ according to:

$$
h=\alpha\left(d-d_{0}\right) \text { with } \alpha=0.19 \text { and } d_{0}=0.43 \mathrm{~nm} .
$$

This relationship is similar to the Mitchell law obtained by STM measurements for the growth of $\mathrm{Au}$ on $\mathrm{TiO}_{2}(110)$ [42].

\section{Preliminary results in catalysis}

The reactivity of $\mathrm{Pd}$ nanoparticles stabilized on prestructured HOPG surfaces was tested in organic synthesis for the formation of alkenyl-aryl bonds via Heck reaction. This cross-coupling reaction is a very important and powerful tool for carbon-carbon bond forming process. According to recent results [43], iodobenzene and methyl acrylate were reacted in a 2:1 mixture of toluene and dimethylformamide (DMF) in the presence of $\mathrm{Pd} / \mathrm{HOPG}$ surfaces. The reaction was carried out over $373 \mathrm{~K}$ for $12 \mathrm{~h}$. The results reveal that the desired alkene was obtained in $35 \%$ isolated yield using an extremely low amount of palladium, i.e., ca. $0.38 \mu$ equiv (see Fig. 7). It is worth to note that this amount of $\mathrm{Pd}$ is extremely low compared to that traditionally used for Heck couplings [43,44]. Thus, the use of Pd supported on HOPG as catalyst results in high catalytic activity. Remarkably, no ligand was required in this coupling to obtain the desired alkene.

\section{Conclusion}

We have shown that Pd clusters can grow with a low size distribution on defects artificially generated on HOPG substrates. These defects are circular pits whose dangling bonds allow the Pd particles to be stabilized on the surface. The number and size of the pits, and in turn the $\mathrm{Pd}$ clusters surface density, can be tuned by means of the $\mathrm{Au}_{5}$ impacts number and the etching time of the HOPG substrate. We evidenced that the height of the $\mathrm{Pd}$ nano-clusters depends linearly on the nano-cluster diameter. Moreover, we highlighted that the cluster number per perimeter unit increases with $\mathrm{Pd}$ amount until saturation (at $0.75 \mathrm{ML}$ ), and that, within this coverage range, the diameter distribution is centered at $4-5 \mathrm{~nm}$. We have also shown that even after annealing up to $500 \mathrm{~K}$ the $\mathrm{Pd}$ nano-clusters remain intact in the graphite surface layer.

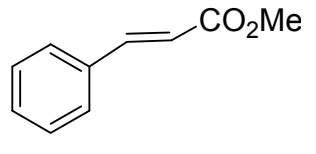

Fig. 7. Heck reaction of iodobenzene and methyl acrylate.

Preliminary results evidenced that this system seems to be a good candidate for Pd catalysis. Further investigations will be done in order to understand and optimize this aspect.

This work has been supported by the Swiss National Science Foundation, the CNRS and C'Nano Grand Est foundation.

\section{References}

1. M. Eikerling, A. Kornyshev, A. Kucernak, Phys. Today 59, 38 (2006)

2. P. Ruvinsky, A. Bonnefont, M. Houlle, C. Pham-Huu, E. Savinova, Electrochim. Acta 55, 3245 (2010)

3. U. Heiz, F. Vanolli, A. Sanchez, W.D. Schneider, J. Am. Chem. Soc. 12, 9668 (1998)

4. U. Heiz, A. Sanchez, S. Abbet, W.D. Schneider, J. Am. Chem. Soc. 121, 3214 (1999)

5. S. Abbet, U. Heiz, A.M. Ferrari, L. Giordano, C. Di Valentin, G. Pacchioni, Thin Solid Films 400, 37 (2001)

6. K. Judai, S. Abbet, A.S. Woerz, U. Heiz, C.R. Henry, J. Am. Chem. Soc. 126, 2732 (2004)

7. A.S. Woerz, K. Judai, S. Abbet, U. Heiz, J. Am. Chem. Soc. 125, 7964 (2003)

8. A.S. Woerz, K. Judai, S. Abbet, J.M. Antonietti, U. Heiz, A. Del Vitto, L. Giordano, G. Pacchioni, Chem. Phys. Lett. 399, 266 (2004)

9. M. Haruta, Catal. Today 36, 153 (1997)

10. X. Valden, M.Lai, D. Goodman, Science 281, 1647 (1998)

11. M. Haruta, S. Tsubota, T. Kobayashi, H. Kageyama, M. Genet, B. Delmont, J. Catal. 144, 175 (1993)

12. R. Meyer, C. Lemire, S.K. Shaikhutdinov, H.J. Freund, Gold Bull. 37, 72 (2004)

13. M. Chen, D. Goodman, Science 306, 252 (2004)

14. A. Sanchez, S. Abbet, U. Heiz, W.D. Schneider, H. Haekkinen, R.N. Barnett, U. Landman, J. Phys. Chem. A 103, 9573 (1999)

15. B. Yoon, U. Landman, A.S. Worz, J.M. Antonietti, S. Abbet, K. Judai, U. Heiz, Science 307, 403 (2005)

16. S. Pandelov, U. Stimming, Electrochim. Acta 52, 5548 (2007)

17. J. Meier, J. Schiotz, P. Liu, J.K. Norskov, U. Stimming, Chem. Phys. Lett. 390, 4400 (2004)

18. B. Brandt, T. Schalow, M. Laurin, S. Schauermann, J. Libuda, H.J. Freund, J. Phys. Chem. C 111, 938 (2007)

19. H.J. Freund, Catal. Today 117, 6 (2006)

20. S. Lee et al., J. Phys. Chem. C 114, 10342 (2010)

21. W. Zou, A. Lewera, R. Masel, P. Bagus, A. Wieckowski, J. Phys. Chem. B 110, 13393 (2006)

22. W. Zhou, J.Y. Lee, J. Phys. Chem. C 112, 3789 (2008)

23. Y. Gimeno, C.A. Hernandez, P. Carro, S. Gonzalez, R.C. Salvarezza, A.J. Arvia, J. Phys. Chem. B 106, 4232 (2002)

24. S. Gibilisco, M. Di Vece, S. Palomba, G. Faraci, R.E. Palmer, J. Am. Chem. Soc. 125, 84704 (2006) 
25. J. Grunwaldt, C. Kiener, C. Wogerbauer, A. Baiker, J. Catal. 181, 223 (1999)

26. I.M. Goldby, L. Kuipers, B. von Issendorff, R.E. Palmer, Appl. Phys. Lett. 69, 2819 (1996)

27. J.D. Grunwaldt, M. Maciejewski, O.S. Becker, P. Fabrizioli, A. Baiker, J. Catal. 186, 458 (1999)

28. T. Irawan, I. Barke, H. Hövel, Appl. Phys. A 80, 929 (2005)

29. Y.J. Zhu, A.A. Schnieders, D. Jennifer, T.P.J. Beebe, Langmuir 18, 5728 (2002)

30. J.D. McBride, B. van Tassell, R.C. Jachmann, T.P.J. Beebe, J. Phys. Chem. B 105, 3972 (2001)

31. Y. Zhu, J.D. McBride, T.A. Hansen, T.P.J. Beebe, J. Phys. Chem. B, 2010 (2001)

32. G. Braeuchle, S. Richard Schneider, D. Illig, R. Beck, H. Schreiber, M. Kappes, Nucl. Instr. Methods B 112, 105 (1996)

33. G. Braeuchle, S. Richard Schneider, D. Illig, J. Rockenberger, R.D. Beck, M.M. Kappes, Appl. Phys. Lett. 67, 5254 (1995)

34. H. Hövel, I. Barke, Prog. Surf. Sci. 81, 53 (2006)
35. H. Hövel, T. Becker, A. Bettac, B. Reihl, M. Tschudy, E. Williams, J. Appl. Phys. 81, 154 (1997)

36. M. Limat, G. Foti, M. Hugentobler, R. Stephan, W. Harbich, Catal. Today 146, 378 (2009)

37. M. Hugentobler, S. Bonanni, A. Sautier, W. Harbich, Eur. Phys. J. D, DOI: 10.1140/epjd/e2010-10520-5 (2011)

38. H. Jodicke, R. Schaub, A. Bhowmick, R. Monot, J. Buttet, W. Harbich, Rev. Sci. Instrum. 71, 2818 (2000)

39. L. Seminara, P. Convers, R. Monot, W. Harbich, Eur. Phys. J. D 29, 49 (2004)

40. I. Horcas, R. Fernandez, J.M. Gomez-Rodriguez, J. Colchero, J. Gomez-Herrero, A.M. Baro, Rev. Sci. Instrum. 78, 013705 (2007)

41. C.M. Whelan, C. Barnes, J. Appl. Surf. Sci. 119, 288 (1997)

42. C.J. Mitchell, A. Howard, M. Carney, R.G. Egdell, Surf. Sci. 490, 196 (2001)

43. C. Diebold, S. Schweizer, J.M. Becht, C. Le Drian, Org. Biomol. Chem. 8, 4834 (2010)

44. I.P. Beletskaya, A.V. Cheprakov, Chem. Rev. 100, 3009 (2000) 